\title{
Assessment and Evaluation- In Perspective of Medical Education
}

\author{
Vageriya $\mathrm{V}^{*}$ \\ Department of Child Health Nursing, Manikaka Topawala Institute of Nursing, India \\ *Corresponding author: Vipin Vageriya, Department of Child Health Nursing, \\ Manikaka Topawala Institute of Nursing, India, Tel: 7874038375; Email: \\ vipinvageriya.nur@charusat.ac.in
}

Mini Review

Volume 2 Issue 4

Received Date: June 26, 2018

Published Date: July 13, 2018

\section{Abstract}

Education is the backbone of the any nation. It decides the economical and social growth of people in that country. Medical education is based on learner skills and practice. Without practice a person cannot work in this field.

The aim of this paper is to describe the various assessment uses in medical education.

There is huge difference in traditional and modern education. Students of 21st century are technology based so teacher must be equipping himself with technology. Now a day's word teaching is replaced by term learning. Students having already the entire subject related material in their computer or mobile. The work of teacher is to explain about the concept. During assessment of teaching, 2 methods are very familiar, which are formative and summative assessment.

Formative assessment is carried out by a teacher to find the knowledge of a learner at the end of each chapter or unit. The teacher can also evaluate his class room or teaching performance after each lecture.

Summative assessment is carried out at the end of semester or year to evaluate the overall performance of a candidate. It is also known as term examination or cumulative examination. Now a day's many new methods are available for teaching in medical education like demonstration, simulation.

Conclusion: Clinical simulation and objective structured clinical examination (OSCE) are new methods used for assessment of medical students.

Keywords: Assessment; Evaluation; Concept; Knowledge; Practice; Formative and Summative assessment

Abbreviations: OSCE: Objective structured clinical examination; OSCE: An objective structured clinical examination; OSPE: Objective Structured Practical Examinations.

\section{Introduction}

Medical education is quiet differ from the technical and vocational education. Medical education applies the theories directly into practice. It is a skill based profession. It is branch of medical science which deals with human body for the prevention and cure of any diseases.

Teaching plays a vital role in the life of human being. It is two way process, where teacher deliver the content and students ready to grasp the concept of the content. In ancient time, the education was given by Guru to their 
pupils in Ashram's known as Gurukul. Teaching is a skill based job, so we can say; it is an art and science. Teaching used to reflect the passion and beauty of the delivering content to learner. It is an direct interaction between teacher and learner [1].

Knowledge is the wealth of $21^{\text {st }}$ century. Teaching and learning both are the parallel step to gain the knowledge. Now a day's teaching is the learner centric.

Teaching is a complex, honest and regular activity that involves mastery over the content and concept. Teaching includes many features like classroom control, organization of content, and command of teaching skills. Teaching consists not only of instruction, it also include thinking process and decision making capability of students [2].

Assessment is derived from Latin word which means "to sit beside and judge". It is used to describe the systematic gathering of information about what the learner should know at the end of each unit or lesson. Some of the people link assessment with intelligence, IQ level, marks or percentages. It also creates badges like excellent, good, average or poor. Assessment itself is very broad term, which includes knowledge, attitude, self learning, commitment etc. [3].

More specifically, classroom assessment refers to the process of gathering, recording, interpreting, using and communicating information about their progress and achievement during the development of knowledge, concepts, skills and attitudes.

\section{Assessment}

Assessment is the state or process of understanding the position of student in class. It includes observation, weekly examination and regular progress report.

\section{Types of Assessment}

Formative assessment: It is an assessment which is carried out by a teacher to find the knowledge of a learner at the end of each chapter or unit. The frequency of assessment will be weekly, fortnight, monthly or quarterly. A learner can adopt new principles to improve his performance in next examination.

- Example: class test, quiz, assignment, viva, oral presentation, case studies, lab report etc.
Summative assessment: It is an assessment which is carried out at the end of semester or year to evaluate the overall performance of a candidate. It is also known as term examination or cumulative examination. It will be in term of percentage, grades or marks. It is also useful for the measurement of course outcome. It is prepared to determine the extent to which the instructional objectives have been achieved. This report is very useful for accreditation, grant and marketing of institute. "Summative" assessment is also known as "evaluation."

\section{Evaluation}

Evaluation is the process in which a person observes the performance of someone. It might be direct or indirect evaluation to observe the candidate. It gives an idea about the quality of education and position of learner.

Evaluation should be always valid, reliable, acceptable, feasible and useful. It should create strong impact in the right direction. The goals of evaluation should be clear from the start (Table 1).

\begin{tabular}{|c|c|}
\hline Assessment & Evaluation \\
\hline Is ongoing process & $\begin{array}{c}\text { Provides closure of } \\
\text { observation }\end{array}$ \\
\hline Improves quality of learner & Judges quality of learner \\
\hline Individualized approach & Applied against standards \\
\hline It does not mean grade & It is Grade \\
\hline $\begin{array}{c}\text { Provides feedback } \\
\text { It is completely Process- } \\
\text { oriented }\end{array}$ & Shows shortfalls \\
\hline It is the means & It is the end \\
\hline
\end{tabular}

Table 1: Difference between Assessment and Evaluation.

According to the findings of some research paper, problem-based learning is the most effective assessment method from the student point of view. Thus, to improve the teaching and learning processes, the following items are suggested:

$>$ Enhance student understanding by arranging more problem-based sessions in class. The style of problembased learning can also be varied by giving students a current topic of interest and initiating debate. Realworld case studies are also encouraged.

$>$ Inviting guest lecturers to give lectures on real-life experience on particular issues in the industry, which is usually lacking in the academic environment?

$>$ Assigning more marks toward other weaker assessment methods such as closed-book and openbook mid-semester tests, to achieve the balance among all assessment methods in the course [4]. 
A study was conducted to find out perception of the medical students of KIMS, Bhubaneswar regarding the prevailing system of teaching methods. The objective of the research was to evaluate the extent to which students are benefited by teaching methods. Another purpose was to obtain the views and suggestions of students about various aspects of the current medical education.

Total 337 participants were selected from 4 semesters for this study. A set of questionnaires were put and directed to choose the appropriate option as per the likert scale. The response were collected and analyzed. 51.83\% of the total respondents agreed that topics during normal lectures are interesting, $77.02 \%$ stated normal lecture as the most effective method of teaching followed by group discussion $68.02 \% .67 .07 \%$ are of the view that the faculty members are having good communication skill and $62.96 \%$ of them found that the faculty members are approachable, $82.83 \%$ of the participants agreed that black board teaching as the better mode of teaching, so also $55.87 \%$ agreed that audio visual aids as a useful mode of teaching, $56.10 \%$ of the participants agreed that the number of practical (clinical) classes should be more than the theory classes. The study concluded that planning for effective faculty development programs is required. These programs are to be tailored to teachers needs about their ability to guide students' learning. The study result will encourage other faculty to work with their students in establishing what the students' preferred and least preferred teaching styles are and the reasons for it [5].

\section{Methods Uses for Medical Student's Evaluation Are}

\section{Clinical Simulation}

As we all know, medical education is practical and skill based area. Medical education is based on cognitive, psychomotor, and affective domains of learning. Simulation is an important methodology in filling the gap between theory and practical in medical education. Many of reviews indicate that simulation-based medical education can improve knowledge and skills and, increasingly, improve patient outcomes.

Clinical simulation is a systematic process which includes the formation of a case scene and handover to students for further analysis and interpretation.

- Example: A 36 years old patient has admitted in the medical ward with the chief complain of abdominal pain, nausea, lack of appetite, insomnia. The students have to apply his theoretical as well as practical knowledge for the finding of correct diagnosis. The medical student will learn how to communicate with the patient and how to document the information. Some students will undergo with electronic manikin to learn the concept of particular diseases [6].

Simulation is the artificial representation of a complex concept of medical related subjects like anatomy, physiology, medicine, pathology etc. It aims to facilitate learning through observation, reflection, feedback, and practice. It minimize the risk associated with patient. Medical simulation offers numerous potential strategies for comprehensive and practical training, and safer patient care. It is the best way to learn. It promotes experiential and reflective learning. It is also a key strategy to teach crisis resource management skills. Simulation can benefit the individual learner, the multidisciplinary team, and the hospital as a whole [7].

\section{The Simulation and its Uses are Classified Into Five Groups which are}

Low-technology: it is not based on technology. It is very low cost dummy. It is useful for the knowledge and to acquire the concept of anatomy, physiology. It impact on psychomotor skills.

Screen-based computer simulators: In this some software are used for training and assessment of clinical symptoms, history taking etc.

Standardized patients: here are some live patients are available in the form of actors. They are trained for particular diseases. It helps to learn students about how to collect history, physical examination, communication skills and attitude of patient.

Complex task trainers: It is computer-based simulators. It is used for complicated procedures like ECG, Ventilator care, CPR, lumber puncture.

Realistic patient simulators: computer-based mannequins used for high-fidelity replication of complex and high-risk clinical conditions in lifelike settings.

\section{Advantages of Simulation Based Learning}

It relieves the risk of any wrong step.

$>$ Any time, any where students can perform it.

$>$ It enables students to learn the concept of particular procedure.

$>$ Students able to apply skills and knowledge into practice.

$>$ It works as bridge between theory and practical.

$>$ It is in expensive.

$>$ It develops interest among students. 


\section{Nursing \& Healthcare International Journal}

Person can develop situation according to her need.

It eliminates the ethical issues like safety and confidentiality.

Repeated practice of procedure.

\section{OSCE}

An objective structured clinical examination (OSCE) is a modern type of examination and demonstration method often used in medical education courses. It is the multidimensional practical examination of clinical skills, as a tool for assessing clinical competence.

Most medical colleges established the Objective Structured Clinical Examination (OSCE) to evaluate the communication skills of undergraduate medical student. An OSCE consists of several stations with different tasks and aims to simulate real clinical encounters between physician and patient [8].

- Objective: Examiners use a checklist for evaluating the students.

- Structured: it is well organized plan in which student observe the same problem and performs the same tasks in the same time.

- Clinical: The tasks are representative of those faced in real clinical situation.

OSCE includes various stations like station-1, 2, 3, 4, 5. Each station has some instrument, dummy patient, case file, case study etc. The student has to undergo with each station ad perform the procedure as desired by teacher. The time will be fix for each statement. The key to a successful OSCE/ OSPE is Careful Planning.

\section{The Steps in Planning and Implementing an OSCE/OSPE}

Prepare the clear objective of procedure

$>$ Identify the Practical aspects like hand washing, weight measuring etc

$>$ Select the procedure

$>$ Break into Sub- Tasks

$>$ Assign marks to each step

$>$ Set up Stations

$>$ Conduct after orienting students and examiners

$>$ Make Notes of the process and review

$>$ Analyze the results and use the same for student assessment

- Example: A client admitted with Jaundice in hospital with variety of complains. Imagine OSCE have 5 stations, Station-1- Do hand washing
Station-2- Interact with patient

Sation-3- Find out instrument help in diagnosis of Jaundice

Station-4- Perform physical examination for Jaundice Sation-5- Document the case

Here a student's has to apply knowledge of anatomy, physiology, pediatric, microbiology etc. It is an effective method of demonstration and examination.

\section{The Basic Steps in Conduction of an OSCE Exam Include}

Identify member of OSCE team

Find the Skills to be assessed on each station

$>$ Objective marking schemes

$>$ Recruitment and training of the standardized patients.

$>$ Logistics of the examination process (Table 2).

\begin{tabular}{|c|c|}
\hline Advantage & Disadvantage \\
\hline $\begin{array}{l}\text { 1. Same and common case } \\
\text { scenarios for all students }\end{array}$ & Expensive \\
\hline 2. Availability & Time consuming \\
\hline $\begin{array}{l}\text { 3. No harmful and adverse } \\
\text { situation happen }\end{array}$ & $\begin{array}{c}\text { Less emotion and verba } \\
\text { comment }\end{array}$ \\
\hline 4. Ethically approved & $\begin{array}{l}\text { Text scenario may not } \\
\text { present in real life } \\
\text { situation }\end{array}$ \\
\hline $\begin{array}{l}\text { 5. Feedback can be taken from } \\
\text { learner }\end{array}$ & \\
\hline 6. Allows for Recall & \\
\hline $\begin{array}{l}\text { 7. Stations can be tailored to } \\
\text { level of skills to be assessed }\end{array}$ & \\
\hline 8. Allows for teaching audit & \\
\hline $\begin{array}{l}\text { 9. Allows for demonstration of } \\
\text { emergency skills }\end{array}$ & \\
\hline
\end{tabular}

Table 2: Advantage and disadvantages of OSCE.

\section{Objective Structured Examinations (OSPE)}

\section{Practical}

It is another method of practical examination and assessment tool.

\section{Conclusion}

Assessment and Evaluation are an ongoing process which is the best standard in assessing the overall performance of the student. It helps to achieve the goal of an organization. It helps to determine the lacking point of an institute like poor result, teacher performance etc. 
Study concludes that following are the Challenges in $21^{\text {st }}$ Century Education

$>$ How to improve Student Engagement in daily class room

$>$ How to equip students with the $21^{\text {st-century }}$ knowledge, skills and practice

$>$ How to allow continuous improvement in curricula and syllabus

$>$ How to Ensure appropriateness of examination system

$>$ How to ensure lifelong learning of teacher and students

How to teach a large class eg 100 students in a coaching

\section{References}

1. Fitzpatrick JJ (2004) Evaluating teaching effectiveness. Nursing Education Perspectives 25(3): 109.

2. Owen S (1992) Devising a checklist to evaluate the non- verbal aspects of teaching skills and delivery. Nurse Education Today 12(5): 392-395.

3. Gibbs T, Brigden D, Hellenberg D (2014) Assessment and evaluation in medical education, South African Family Practice 48(1): 5-7.
4. Le KN, Tam VWY (2007) A survey on effective assessment methods to enhance student learning. Australasian Journal of Engineering Education 13(2): 13-19.

5. Dash SK, Patro S, Kumar B (2013) Teaching Methods and Its Efficacy An Evaluation by the Students" Journal of Indian Acad Forensic Med. 35(4): 321-324.

6. Bland AJ, Topping A, Wood B (2011) A concept analysis of simulation as a learning strategy in the education of undergraduate nursung students. Nurse Educ Today 31(7): 664-670.

7. Datta R, Upadhyay K, Jaideep C (2012) Simulation and its role in medical education. Med J Armed Forces India 68(2): 167-172.

8. Cömert M, Zill JM, Christalle E, Dirmaier J, Härter M, et al. (2016) Assessing Communication Skills of Medical Students in Objective Structured Clinical Examinations (OSCE) - A Systematic Review of Rating Scales. PLoS ONE 11(3): e0152717. 